\title{
Reproductive Health Service Utilization and Associated Factors Among Female Adolescents in Kachabirra District, South Ethiopia: A Community Based Cross Sectional Study
}

\author{
Teshale Tigistu Lejibo", Sahilu Assegid ${ }^{2}$, Muktar Beshir², Tilahun Beyene Handiso ${ }^{2}$ * \\ ${ }^{1}$ Kachabirra District Health Office, SNNPRS, Ethiopia \\ ${ }^{2}$ Institute of Health, Faculty of Public Health, Department of Epidemiology, Jimma University, Jimma, Ethiopia
}

Email address:

tilahunbeyene44@gmail.com (T. B. Handiso)

${ }^{*}$ Corresponding author

\section{To cite this article:}

Teshale Tigistu Lejibo, Sahilu Assegid, Muktar Beshir, Tilahun Beyene Handiso. Reproductive Health Service Utilization and Associated Factors Among Female Adolescents in Kachabirra District, South Ethiopia: A Community Based Cross Sectional Study. American Journal of Biomedical and Life Sciences. Vol. 5, No. 5, 2017, pp. 103-112. doi: 10.11648/j.ajbls.20170505.14

Received: June 6, 2017; Accepted: June 19, 2017; Published: October 20, 2017

\begin{abstract}
Background: Adolescent girls are at the highest risk of maternal mortality compared to women in their twenties. Reproductive health service utilization among adolescent females is lower when compared with other age groups in Ethiopia. Objectives: The study was aimed to assess the reproductive health service utilization and associated factors among female adolescents of kachabirra district. Methods: Community based cross sectional study was conducted in Kachebirra district. A total of 844 female adolescents participated from 8 randomly selected kebeles (the smallest administrative unit). A pretested structured interview was used. Bivariate and multivariate logistic regression analysis was carried out to assess the association. Statistical significance was declared by $95 \%$ confidence interval of odds ratio. Results: 812 female adolescents with response rate of $96.2 \%$ participated in the study. In this study, $383(47.2 \%, 95 \%$ CI: $43.7-50.6 \%)$ of the female adolescents utilized the reproductive health services. Female adolescent reproductive health service utilization was significantly associated with; living with both parents ( $\mathrm{AOR}=9.63,95 \% \mathrm{CI}$ : 1.237-74.983), age 15-19 years ( $\mathrm{AOR}=3.295,95 \%$ CI: 1.411-7.696), excellent attitudes of health providers (AOR=3.816, 95\% CI: $1.561-9.324$ ) and adequate consultation time (AOR=2.450, 95\% CI: 1.178 5.094). Conclusions: There is low level of female adolescent reproductive health service utilization. Age, living arrangement, attitude of reproductive health service providers and consultation time in the nearby health facilities were significantly associated with female adolescent reproductive health service utilization.
\end{abstract}

Keywords: Female Adolescents, Reproductive Health, Service Utilization

\section{Introduction}

Adolescence is defined as the period between 10 and 19 years of age. It is one of life fascinating and most complex stages, which involves transition from childhood to adulthood and characterized by significant physical, cognitive, behavioral, physiological, psychological and social changes [1].

During adolescence young people starts to define and clarify their sexual values and frequently, start to experiment with sexual behaviors. These typical characteristics of youths put them at increased risk of sexually transmitted infections (STIs), including human immune-deficiency virus (HIV), and unwanted pregnancies. Particularly in sub-Saharan Africa including Ethiopia, they are disproportionately affected by HIV [2].

Adolescent reproductive health (ARH) is becoming ever more important component of global health [3] and is a key intervention to facilitate a healthy transition from adolescence into adulthood [4].

In Ethiopia adolescents comprise of $26.1 \%$ of total population and adolescent females are $25.3 \%$ of total female population. Any modern contraceptive utilization among adolescents is $9.2 \%$ and among currently married adolescents it is $39.6 \%$. The age-specific fertility rate for adolescents is 63 births per 1,000 women of age 15-19 years. Percentage of 
women age less than 20 years who received antenatal care for the most recent pregnancy from a skilled provider is $45.3 \%$ but only $16.1 \%$ received full components of ANC and only $19.2 \%$ delivered in health facility [6].

Even though the adolescents have specific health and development needs, many of them face challenges that hinder their wellbeing including; poverty, a lack of access to health information and services, and unsafe environments [7]. Adolescent females face inter-related barriers that prevent them from accessing facility-based RH services. These include: individual barriers, such as feelings of shame, fear or anxiety about issues related to sexuality and reproduction, lack of awareness about the services available, poor health, or advice-seeking behaviors and the perception that services will not be confidential; socio-cultural barriers, such as social norms which dictate the behavior and sexuality of both young men and women, stigma surrounding sexually active adolescents, cultural barriers which limit the ability of women, girls or certain sub-sets of the population from accessing health services, educational limitations, language differences, the attitudes of health care providers to wards adolescents or their unwillingness to attend their RH needs; and structural barriers, such as long distances to health facilities, lack of facilities for clients with disabilities, inconvenient hours of operation, long waiting times, charging fees for services and lack of privacy [1].

As a result adolescents suffer from life threatening health risks related to early marriage, unwanted pregnancies, unsafe abortions, sexually transmitted infections (STIs) including HIV/AIDS and others [2]. And adolescent girls are at the highest risk of maternal mortality with the risk of pregnancyrelated death twice as high for girls aged 15-19 and five times higher for girls aged 10-14 years compared to women in their twenties. Hence, it is not surprising that despite accounting for only $11 \%$ births worldwide, adolescent women carry $23 \%$ of overall burden of disease due to pregnancy and child birth among women of all ages [8]. Further, pregnant adolescents are more likely than adults to pursue unsafe abortions; an estimated 3.2 million unsafe abortions occur every year among girls aged 15-19 years globally $[9,10]$.

In Ethiopia, unsafe abortion is a leading cause of maternal death and injury [10] and as different studies showed in Ethiopia, 54\% of pregnancies to girls under age 15 years are unwanted; girls under age 15 years are three times more likely to end their pregnancy in abortion. As a result abortion accounts for nearly $60 \%$ of gynecological and almost $30 \%$ of all obstetric and gynecological admissions in Ethiopia [11].

However as different studies show that the RH service utilization among adolescent is lower when compared with other age groups in Ethiopia [12, 13]. From unmarried women aged 15-19 years in Ethiopia, 37\% have an unmet need for contraception and $28 \%$ of recent births were unplanned [10]. Study conducted in Hadiya zone in South Ethiopia showed that, the adolescent sexual and reproductive health service utilization was only $26 \%$ [14].

Even though adolescents are at increased risk of negative reproductive health outcomes [15], adolescents' reproductive health service utilization is low especially in the Southern Ethiopia in which study district is found [14] and nationally in general $[12,13]$.

\section{Methods and Materials}

\subsection{Study Area and Period}

The study was conducted in Kacha-birra district, KambataTambaro zone, South Ethiopia. In the study district, there is one primary hospital, five government and one Non Governmental health centers, 5 private clinics, 6 drug stores and 19 health posts. There are different NGOs working in adolescent reproductive health such as Integrated Family Health Program (IFHP), Ethiopian evangelical Church Mekane-Eyesus central south synod and others. The district is found $327 \mathrm{Kms}$ away from the capital, Addis Ababa and $144 \mathrm{Kms}$ away from the regional capital, Awassa. The total population of Kachabirra district is estimated to be 124,804 in 2015 and estimated total adolescent population of 32,573 (26.1\%) and estimated total adolescent female population of 16,287 (13.05\%). From total population 121,950 (97.7\%) are residents of rural areas and only $2854(2.3 \%)$ are residents of urban areas and majority population lives in the rural areas. The total population of the district is distributed over 21 different kebeles (20 rural and 1 urban kebeles) [32].

The study was conducted from March 02-29/2016. A community based cross-sectional study design was used.

Source population: All female adolescents (age 10-19 years) of the district.

All the female adolescents (age 10-19 years) of the selected kebeles of the district, who lived in the area for a minimum of 6 months included in the study. Those adolescent (age 10-19 years) females who are severely ill were excluded from the study.

\subsection{Sample Size Determination}

Sample size was determined by using the sample size determination formula for single population proportion at confidence level of $95 \%$ Margin of error $\mathrm{d}=5 \%$ and $\mathrm{P}$ taken as $50 \%, \quad \mathrm{n}=(\mathrm{Z} \alpha / 2) 2 \mathrm{P}(1-\mathrm{P}) \quad \mathrm{d} 2=(1.96)^{2} * 0.5(1-0.5) /(0.05)^{2}$ $\mathrm{n}=384$.

Because multistage sampling method was used, multiplied by design effect of 2 , the sample size became 768 . Finally by adding $10 \%$ for non-response rate, the sample size became 844. 


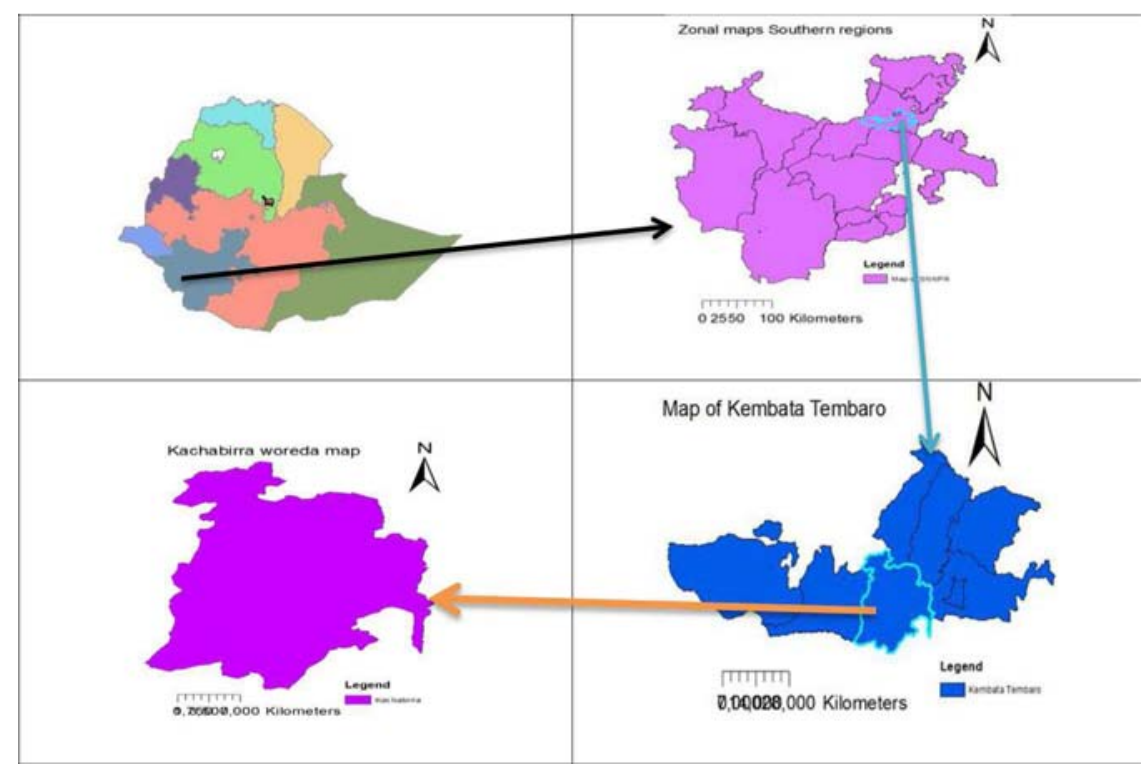

Figure 1. Map of study area.

\subsection{Sampling Technique}

A multi stage sampling technique was used since female adolescents were widely scattered over the whole district.

In the first stage based on WHO guideline [33], from the total of 21 kebeles of the district, $40 \%$ (8 kebeles) were identified by using simple random sampling method. To assure representativeness of the data the sample size was proportionally allocated to 8 selected kebeles, proportionally to their total population.

Then in the second stage from the identified 8 kebeles, total required sample of ( 844 female adolescents (SSU)) were selected.

Random walk method of sampling was used to select households from the selected kebeles.

To apply random walk method first in each kebele six starting points were allocated on a map. Then two of these numbers were selected at random by writing them on pieces of paper. Then after selecting two of the numbers on the map data collection was started at both points. The household nearest to the starting point was included first. Then by spinning a pen, the direction in which to continue was decided and a road was followed to identify the next house holds by using access roads. Then the data collection was continued in this way until the required number of female adolescents in the cluster was reached. In the households with more than one female adolescent, lottery method was used to select one of them.

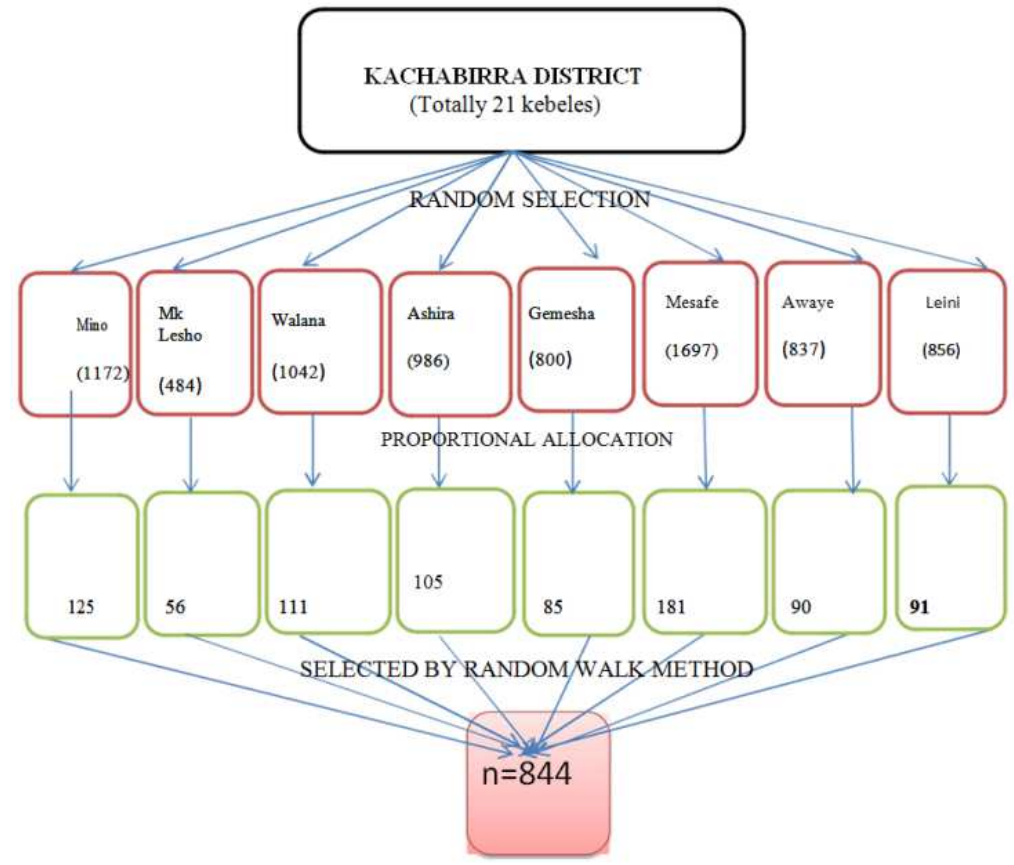

Figure 2. Schematic representation of the sampling procedure, 2016. 


\subsection{Data Collection Procedures}

A structured and pretested questionnaire was used to collect the data. Seven data collectors who were female and diploma graduates of nursing, whose age not more than 25 years. There were also two supervisors who were BSc nurses to follow, check, support and correct the activities of data collectors.

\subsection{Data Quality Control}

The quality of data was assured through careful design, translation and retranslation, pretest of the questionnaire and proper training of the data collectors and supervisors on the data collection procedures. Questionnaire and consent form were developed in English then translated to Kambatissa language and finally back translated to English by another translator to assure the consistency. Structured interview was used as a technique of data collection. A pre-test was conducted in $5 \%$ of the sample population (42 female adolescents) in kebele out of the 8 selected kebeles (Itte kebele), before conducting of the study. Based on the pre-test result, the questionnaire was corrected. Before data collection, training was given for data collectors and supervisors about the aim of the study, data collection technique and the idea of the questionnaire by discussing questions one by one in order to have a common sense on all questions. In order to assure the completeness of questionnaire, the collected data was checked daily by supervisor and investigator, and the necessary feedback was offered to data collectors in the next morning before starting data collection. Each village was visited twice a day (morning and afternoon) in order to reach female adolescents who are in different shifts in school.

\subsection{Study Variables}

\subsubsection{Dependent Variable}

Reproductive health service utilization

\subsubsection{Independent Variable}

(1) Socio-demographic and economic variables

(i) Educational status

(ii) Parental educational status

(iii) Living arrangement

(iv) Schooling status

(v) Age

(vi) Marital status

(vii) Personal knowledge of ARH

(viii) Personal sexual experience

(ix) Level of family income

(x) Parental occupation

(2) Health facility related variables

(i) Perceived Availability of medical services

(ii) Perceived Attitude of providers

(iii)Perceived Privacy of the patient

(iv)Perceived Consultation time

(v) Perceived Waiting time

\section{(vi)Physical proximity}

\subsection{Operational Definitions}

Adolescent reproductive health services: particularly considered in this study are family planning, condom, VCT, STI treatment, IEC, comprehensive abortion care, maternal services such as ANC, PNC and delivery [35].

Family income: Monthly income below 1205 ETB was considered as poor and above 1205 was considered as rich based on World Bank International poverty line 2014 [36].

Contraceptive service utilization: is defined as ever utilization of any modern contraceptives.

Personal Knowledge of $R H$-Was measured by asking eight multiple choice and true/false questions. Those who answer above median score were, considered as knowledgeable and below median score were considered as not knowledgeable.

Physical proximity: is distance from adolescents' home to $\mathrm{RH}$ service center to which is less than $10 \mathrm{~km}$.

Reproductive health service utilization: is defined as ever utilization of at least one of the reproductive health services any where whether in government or private health institutions. This was measured through the dichotomous response (yes or no). The positive response was further validated with questions on the type of RH services utilized.

Severely ill:-those adolescents who can't respond due to illness or difficulty of responding.

Perceived waiting time:-is time taken after arrival to $\mathrm{RH}$ service center and starting of being served, from adolescent females view point.

Kebele: refers to the smallest administrative unit.

\subsection{Data Processing and Analysis Procedures}

The data gathered through the structured questionnaire was entered using Epidata version 3.1 and exported to SPSS version 20 for analysis. Frequencies mean and percentage were used to describe the data. Multicollinearity was checked by variance inflation factor. Model fitness was checked by using Hosmer-lemeshow goodness-of-fit-test. Binary logistic regression analysis was carried out. Crude association between dependent and independent variables was assessed by bivariate logistic regression and its strength was presented using odds ratios and 95\% confidence intervals. Bivariate followed by multivariate logistic regression analysis was also carried out to control confounding effects of variables. Variables with $\mathrm{P}$ value less than 0.25 in binary logistic regression were entered into multiple logistic regressions. Based on adjusted OR and 95\% CI, variables which are associated with dependent variable were identified.

\subsection{Ethical Consideration}

Before the study begun ethical clearance was obtained from the ethical review committee of Jimma University. Official permission was secured from the district health office. The respondents were informed about the objective and purpose of the study and written consent was obtained 
from parents and participants. Confidentiality of the information was assured and information was collected secretly.

\section{Result}

Out of 844 participants interviewed 812 completely responded and 32 left the interview without completing the total questions provided, therefore omitted from the analysis. As a result the final response rate became $96.2 \%$.

\subsection{Socio-demographic and Economic Characteristics of Respondents}

The mean age of the participants was 15.47 (SD 2.266, min 10 and max 19) years. Kambata constituted 696 (85.7\%) and Hadiya $96(11.8 \%)$ of total ethnic group of the participants. $648(79.8 \%)$ of the participants were Protestants, $107(13.2 \%)$ were orthodox and $36(4.4 \%)$ were catholic. 540 $(67.7 \%)$ of participants were in school and $262(32.3 \%)$ were out school. $116(14.3 \%)$ of the participants were married and $694(85.5 \%)$ were single. $596(73.4 \%)$ of participants were living with both father and mother, 102 (12.6\%) living with father only and $40(4.9 \%)$ were living with mother only. 541 $(66.6 \%)$ of participants scored mean and above mean score and $271(33.4 \%)$ scored below mean score from the knowledge questions. 207 (25.5\%) of female adolescents' mothers level of education was no formal education, 417 $(51.4 \%)$ of female adolescents' mothers' educational levels were primary and 177 (21.8\%) of female adolescent mothers' educational level were secondary and above. 144 (17.6\%) of female adolescents' fathers' were no formal education. 434 (53.4\%) of female adolescents' fathers' educational level were primary, $173(21.3 \%)$ of female adolescent fathers educational level were secondary and $43(5.3 \%)$ of female adolescents' fathers' educational levels were college and above.

Only $112(13.8 \%)$ of participants were above and 700 $(86.2 \%)$ below the poverty line. Parental occupation of the participants was $49(6 \%)$ formal employment, $668(82.3 \%)$ were farmer, and $43(5.3 \%)$ and $52(6.4 \%)$ were laborer and Self-employed respectively.

\subsection{Reproductive Health Related Characteristic}

$253(31.2 \%)$ of adolescent females have boyfriends, 27 (3.4\%) have two or more sexual partners and $133(16.4 \%)$ have ever had sex (sexual experience). 88 (10.8\%) had sex with in the last one year. $18(2.3 \%)$ of the female adolescents have had sex with two or more partners and only 89 (11\%) used condom or other contraceptive during the sex. Condom was utilized by $34(4.2 \%)$ of adolescents, emergency contraceptive was used by $32(3.9 \%)$, pills by $14(1.7 \%)$ and other contraceptives by $16(1.8 \%)$ of the respondents.

\subsection{Health Facility Related Characteristics}

$255(61.3 \%)$ of participants who utilized the service responded that the privacy of clients was not adequate while $148(38.6 \%)$ of them responded that privacy was adequate in their nearby RH service center. Out of those who have utilized the service, $223(58.2 \%)$ responded that health providers in their nearby RH service center spend adequate consultation time counseling them while 160 (41.8\%) of them responded that they didn't spend adequate consultation time. $203(53 \%)$ of participants who utilized the service, responded that waiting time was too long and 180 (47\%) of them responded that waiting time was reasonable in their nearby RH service center. Out of those who utilized the service, $174(45.4 \%)$ responded that availability of the medical services was adequate, while 208 (54.6\%) of them responded that availability of the medical services was not adequate. 95 (24.8\%) of those female adolescent utilized the service responded that the attitude of health workers in the nearby RH service center was excellent, 126 (32.9\%) responded that the attitude of health workers in the nearby RH center was good and $162(42.3 \%)$ of them responded that the attitude of health workers in the nearby RH center was not so good. $63.5 \%$ of participants responded that they have RH service center within 30 minute walk distance from their home.

\subsection{ARH Service Utilization}

$383(47.2 \%)(95 \% \mathrm{CI}: 43.7-50.6 \%)$ of participants had ever used at least one of the RH services the most commonly utilized services being VCT 310 (38.2\%) and IEC 257 (31.7) followed by ANC, PNC and delivery 83 (10.2\%), contraceptive $79(9.75 \%)$, condom $62(7.6 \%)$, abortion care $46(5.7 \%)$ and STI treatment $25(3.1 \%) .111(13.7 \%)$ of participants utilized at least one of the RH services within the last six months.

\subsection{Results of Bivariable Analyses}

In order to identify factors associated with ever utilization of female adolescent reproductive health service, bivariate analysis was carried out (Table 1).

Table 1. Bivariate analysis of factors associated with reproductive health service utilization among adolescent females of Kachabirra district, 2016.

\begin{tabular}{llll}
\hline \multirow{2}{*}{ Variables } & \multicolumn{2}{l}{ RH Service utilization } & Crude OR \\
\cline { 2 - 4 } & Yes & No & 95\% CI \\
\hline Age & 120 & 143 & 1 \\
$10-14$ & 263 & 286 & $1.096(.816-1.472)$ \\
$15-19$ & & & 1 \\
Marital status & 298 & 396 & $.292(.190-.449)$ \\
Single & 85 & 33 & $.243 *$ \\
Others & & & $.000^{*}$ \\
Educational status & & \\
\hline
\end{tabular}




\begin{tabular}{|c|c|c|c|c|}
\hline \multirow{2}{*}{ Variables } & \multicolumn{2}{|c|}{ RH Service utilization } & \multirow{2}{*}{$\begin{array}{l}\text { Crude OR } \\
95 \% \text { CI } \\
\end{array}$} & \multirow{2}{*}{$P$ value } \\
\hline & Yes & No & & \\
\hline no formal education & 38 & 40 & 1 & 0.416 \\
\hline grade $1-8$ & 176 & 217 & $1.171(.720-1.905)$ & $.124 *$ \\
\hline Secondary and above & 169 & 172 & $.967(.591-1.582)$ & 0.893 \\
\hline \multicolumn{5}{|l|}{ Schooling status } \\
\hline in school & 248 & 302 & $1.294(.964-1.738)$ & $.086^{*}$ \\
\hline Out school & 135 & 127 & 1 & \\
\hline \multicolumn{5}{|l|}{ Living arrangement with } \\
\hline Others & 67 & 7 & 1 & 0 \\
\hline Father & 20 & 20 & $12.124(5.074-28.971)$ & $.000 *$ \\
\hline Mother & 45 & 57 & $9.571(3.538-25.891)$ & $.000 *$ \\
\hline Both father and mother & 251 & 345 & $13.156(5.939-29.143)$ & $.000^{*}$ \\
\hline \multicolumn{5}{|l|}{ Mothers educational Status } \\
\hline no formal education & 102 & 105 & 1 & 0.76 \\
\hline grade $1-8$ & 195 & 222 & $1.106(.792-1.544)$ & 0.554 \\
\hline Secondary and above & 10 & 1 & $1.152(.776-1.711)$ & 0.483 \\
\hline \multicolumn{5}{|l|}{ Fathers educational status } \\
\hline no formal education & 203 & 231 & 1 & 0.954 \\
\hline grade $1-8$ & 77 & 96 & $1.061(.727-1.549)$ & 0.759 \\
\hline Secondary and above & 103 & 102 & $1.042(.687-1.579)$ & 0.848 \\
\hline \multicolumn{5}{|l|}{ Sexual experience } \\
\hline sexually experienced & 113 & 20 & $8.635(5.237-14.237)$ & $.000^{*}$ \\
\hline Not sexually experienced & 265 & 405 & 1 & \\
\hline \multicolumn{5}{|l|}{ Personal Knowledge RH } \\
\hline Knowledgeable & 261 & 280 & $.878(.655-1.177)$ & 0.385 \\
\hline Not knowledgeable & 122 & 149 & 1 & \\
\hline \multicolumn{5}{|l|}{ Family income } \\
\hline below 1205 ETB & 325 & 375 & $1.239(.831-1.848)$ & 0.292 \\
\hline above 1205 ETB & 58 & 54 & 1 & \\
\hline \multicolumn{5}{|l|}{ Parent occupation } \\
\hline 'farmer' & 317 & 351 & 1 & 0.828 \\
\hline formal employment & 22 & 27 & $1.108(.619-1.986)$ & 0.729 \\
\hline causal labourer & 22 & 21 & $.862(.465-1.598)$ & 0.637 \\
\hline Self-employment & 22 & 30 & $1.232(.696-2.179)$ & 0.474 \\
\hline \multicolumn{5}{|l|}{ Physical proximity } \\
\hline Yes & 263 & 253 & $1.525(1.142-2.036)$ & $.004 *$ \\
\hline No & 120 & 176 & 1 & \\
\hline \multicolumn{5}{|c|}{ Availability of medical service } \\
\hline Adequate & 50 & 124 & $1.449(.783-2.681)$ & $.238^{*}$ \\
\hline Not adequate & 69 & 139 & 1 & \\
\hline \multicolumn{5}{|l|}{ Attitude of health providers } \\
\hline not so good & 48 & 114 & 1 & $.000^{*}$ \\
\hline Good Attitude & 39 & 87 & $2.424(.9965 .901)$ & $.051^{*}$ \\
\hline Excellent & 32 & 63 & $5.254(2.255-12.243)$ & $.000 *$ \\
\hline \multicolumn{5}{|l|}{ PRIVACY } \\
\hline Not Adequate & 71 & 164 & $2.298(1.232-4.286)$ & $.009 *$ \\
\hline Adequate & 48 & 100 & 1 & \\
\hline \multicolumn{5}{|l|}{ Adequate consultation time } \\
\hline Yes & 51 & 155 & $3.584(1.826-7.034)$ & $.000 *$ \\
\hline No & 68 & 109 & 1 & \\
\hline \multicolumn{5}{|l|}{ Waiting time } \\
\hline Reasonable & 53 & 127 & $1.673(.882-3.174)$ & $.115^{*}$ \\
\hline Too long & 66 & 137 & 1 & \\
\hline
\end{tabular}

$1=$ reference category, living arrangement "others"=include relatives, husband or brother/sisters,

Marital status, Others ${ }^{e=}=$ married, separated and divorced, ${ }^{*}=$ candidate for multivariable analysis, religion; 'others' include Muslims, Jove, Adventism

\subsection{Results of Multivariable Analysis}

In multivariable analysis, the Nagelkerke R Square was 0.235 . Thus, around $23.5 \%$ of the ARH service utilization variation is explained by study variables. Multicollinearity was checked by using variance inflation factor.

In multivariable analysis, from total candidate variables, only age, living arrangement, attitude of health providers and consultation time in their nearby RH service center were found to be statistically significantly associated with female adolescent RH service utilization.

Age of participants was found to be statistically significantly associated with female adolescent reproductive health service utilization. Female adolescents of age 15-19 years utilized RHS 3.3 times more likely than those of age 10-14 years (AOR=3.295, 95\% CI: 1.411-7.696).

Living arrangement of the female adolescents was also 
statistically significantly associated with the utilization of female adolescent RH service. The likelihood of RH services uptake was about 9.6 times higher among female adolescents living with both parents than those adolescent females living with others (AOR=9.630, 95\% CI: 1.237-74.983).

Attitude of service providers was also found to be statistically significantly associated with female adolescent RH service utilization. Those female adolescents whose nearby RH service centers are staffed by health providers with excellent attitudes were 4 times more likely to utilize $\mathrm{RH}$ service than those female adolescents whose nearby $\mathrm{RH}$ service centers are staffed by health providers with not so good attitudes ( $\mathrm{AOR}=3.816,95 \% \mathrm{CI}=1.561-9.324)$.

This study revealed that consultation time in the nearby RH service centers was also statistically significantly associated with female adolescent reproductive health service utilization. Those female adolescents with adequate consultation time in their nearby RH service center were 2.4 times more likely utilize female adolescent reproductive health service than those female adolescents with not adequate consultation time in their nearby $\mathrm{RH}$ service center (AOR=2.450, 95\% CI: 1.178-5.094). (Table 2)

Table 2. Multivariable analysis of candidate variables with reproductive health service utilization among adolescent females of Kachabirra district, 2016.

\begin{tabular}{|c|c|c|c|c|}
\hline \multirow{2}{*}{ Variables } & \multicolumn{2}{|c|}{ RH Service utilization } & \multirow{2}{*}{$\begin{array}{l}\text { Adjusted OR } \\
95 \% \text { CI }\end{array}$} & \multirow{2}{*}{ P value } \\
\hline & Yes & No & & \\
\hline \multicolumn{5}{|l|}{ Age } \\
\hline $10-14$ & 120 & 143 & 1 & \\
\hline $15-19$ & 263 & 286 & $3.295(1.411-7.696) * *$ & 0.006 \\
\hline \multicolumn{5}{|l|}{ Marital status } \\
\hline Single & 298 & 396 & 1 & \\
\hline Others & 85 & 33 & $.904(.176-4.634)$ & 0.904 \\
\hline \multicolumn{5}{|l|}{ Educational status } \\
\hline no formal education & 38 & 40 & 1 & \\
\hline grade $1-8$ & 176 & 217 & $2.382(.487-11.658)$ & 0.284 \\
\hline Secondary and above & 169 & 172 & $.928(.184-4.672)$ & 0.928 \\
\hline \multicolumn{5}{|l|}{ Schooling status } \\
\hline in school & 248 & 302 & $.798(.378-1.684)$ & 0.553 \\
\hline Out school & 135 & 127 & 1 & \\
\hline \multicolumn{5}{|l|}{ Living arrangement with } \\
\hline Others & 67 & 7 & 1 & 0.08 \\
\hline Father & 20 & 20 & $1.849(.098-34.863)$ & 0.682 \\
\hline Mother & 45 & 57 & $8.857(.977-80.252)$ & 0.052 \\
\hline Both father and mother & 251 & 345 & $9.630(1.237-74.983) * *$ & 0.031 \\
\hline \multicolumn{5}{|l|}{ Sexual experience } \\
\hline sexually experienced & 113 & 20 & $.657(.241-1.789)$ & 0.411 \\
\hline Not sexually experienced & 265 & 405 & 1 & \\
\hline \multicolumn{5}{|l|}{ Physical proximity } \\
\hline Yes & 263 & 253 & $1.876(.940-3.745)$ & 0.074 \\
\hline No & 120 & 176 & 1 & \\
\hline \multicolumn{5}{|l|}{ Availability of m service } \\
\hline Adequate & 50 & 124 & $1.055(.511-2.179)$ & 0.884 \\
\hline Not adequate & 69 & 139 & 1 & \\
\hline \multicolumn{5}{|l|}{ Attitude of health providers } \\
\hline not so good & 48 & 114 & 1 & 0.009 \\
\hline Good Attitude & 39 & 87 & $2.382(.935-6.069)$ & 0.069 \\
\hline Excellent & 32 & 63 & $4.204(1.684-10.497) * *$ & 0.002 \\
\hline \multicolumn{5}{|l|}{ PRIVACY } \\
\hline Not Adequate & 71 & 164 & $1.077(.512-2.269)$ & 0.845 \\
\hline Adequate & 48 & 100 & 1 & \\
\hline \multicolumn{5}{|l|}{ Adequate consultation time } \\
\hline Yes & 51 & 155 & $2.450(1.178-5.094) * *$ & 0.016 \\
\hline No & 68 & 109 & 1 & \\
\hline \multicolumn{5}{|l|}{ Waiting time } \\
\hline Reasonable & 53 & 127 & $.893(.414-1.926)$ & 0.773 \\
\hline Too long & 66 & 137 & 1 & \\
\hline
\end{tabular}

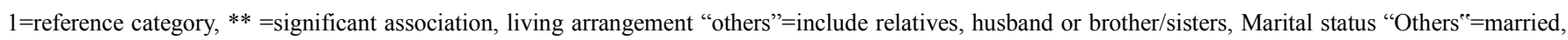
separated and divorced, religion "others" include Muslims, Jove, Adventist

\section{Discussions}

The main focus of this study was to assess the reproductive health service utilization and factors associated with utilization among female adolescents aged (age 10-19 years) in the study district. Ever use of RH services is mainly measured as the practice of adolescents with RH service utilization. The finding of this study showed that the majority 
of female adolescents were not utilizing $\mathrm{RH}$ services in the study district.

About 383 (47.2\%) (95\% CI: 43.7-50.6\%) of participants had ever used at least one of the RH services with the most commonly utilized services being VCT 310 (38.2\%) and IEC 257 (31.7) followed by ANC, PNC and delivery 83 (10.2\%), contraceptive $79(9.75 \%)$, condom $62(7.6 \%)$, abortion care $46(5.7 \%)$ and STI treatment $25(3.1 \%)$ which was almost similar to that of Jimma, which showed that, $41.1 \%$, were ever users of RH services. 34\% of adolescents ever used health services for Information, Education and Communication (IEC) followed by family planning $17.6 \%$. $5 \%$ and $3.1 \%$ of them used health services for STI treatment and abortion care, respectively [12]. But this result is inconsistent with the study conducted in Nepal among higher secondary school students, which showed that, SRH service utilization proportion was lower among female adolescents $(4.3 \%)$. This big difference is because female adolescents in the community have higher proportion of married female adolescents than those female adolescents in school [22].

$253(31.2 \%)$ of adolescent females had sexual partners from this $27(3.4 \%)$ have two or more partners and 133 $(16.4 \%)$ have ever had sex. This is almost lower than that of study conducted in Goba which showed that out of the total participants $58.70 \%$ have had sexual partner, and $52.60 \%$ have had sexual intercourse and this difference is because the Goba study was conducted among urban adolescents where as this one is conducted among rural. In this study, condom or other contraceptives were utilized by $11 \%$ of participants ( $33 \%$ of those have sexual experience) which are the same to that of Goba study that showed that, out those who experienced sexual intercourse, $28.60 \%$ did not use any modern contraception [19].

In this study only age, living arrangement, attitude of service providers and consultation time were found to be statistically significantly associated with RH service utilization.

Female adolescents of age 15-19 years utilized RHS 3 times more likely than those of age 10-14 years, which was almost similar to that of Machakel district where adolescents of age 15-19 years utilized two times that of adolescents of age 10-19 years [21], which may be due to lack of awareness and feeling of shame and fear during the early adolescence.

This study showed that living with both parents increases the utilization of female adolescent reproductive health services among adolescents of the district. This is because family (parental) interaction and communication about $\mathrm{RH}$ services and its importance, which is consistent with the findings of studies, conducted in Jimma, Gonder and Gojjam $[12,18$, and 21]. But this is contradictory to the institution based Study conducted in Zimbabwe [24].

In multivariate analysis, from health facility related factors, attitude of health providers and consultation time were found to be factors affecting female adolescent $\mathrm{RH}$ service utilization, which is consistent with the study conducted in Bahir Dar which showed that barriers to Adolescent RH service utilization are too long waiting hours
(28.4\%), too short consultation hour (25.4\%) judgmental and unfriendly providers $(23.6 \%)$ [28].

This study found that the attitude of the health workers affects the utilization of adolescent female reproductive health service. Because the behavior of health care providers with bad attitude may create discomfort and shame to adolescents, they face the barrier for the utilization of the service. That leave adolescents avoid seeking health care services, which is in line with the study conducted in Eastern Harerge, Kenya and Zambia [29, 30, 31].

In this study, the consultation time in the nearby $\mathrm{RH}$ service center is also identified as a factor that influences utilization of female adolescent reproductive health service. Adequate consultation time in nearby health facility increases the utilization of adolescent female RH service. But there are no literatures to compare the result, because of absence of the studies that assessed the association of consultation time and adolescent reproductive health service utilization. This may be because of adolescents' behavior that they require long consultation time which is because of their preference of telling other cause for their visit to the facility rather than telling directly their $\mathrm{RH}$ related problem until they take the attention of the provider.

As the study design being cross sectional, it is difficult to determine causal relationship between variables. Reports of sexual activities and related behaviors might have been restrained by taboo behaviors. The quantitative nature of study design might not allow for probing into certain areas which needed further qualitative description. Recall bias is might be potential limitation because the information was collected retrospectively. Because of the sensitive nature of the information, accuracy of the information might be limited. Social desirability bias might have resulted in underreporting of the service utilized.

\section{Conclusion and Recommendations}

\subsection{Conclusion}

In general, this study found that reproductive service utilization among female adolescents in the study area was low and socio-demographic and health facility related factors such as age, living arrangement, attitude of RH service providers and consultation time in the nearby health facilities were found to be factors affecting female adolescent reproductive health services utilization in rural kebeles.

\subsection{Recommendation}

Based the study findings, the following recommendations were forwarded:

To Rural districts

(1) The district health offices and health institutions should work on initiation of adolescent RH service utilization by using schools and youth centers in order to address those adolescent females living without mother and father.

(2) Health workers who work in adolescent RH service 
should be trained about adolescent friendly services in order to improve their attitude and approaches towards the service users.

(3) Health facilities should provide adolescent RH service with enough providers and classes to improve the consultation time for adolescent females who visit the health facility for any of RH services.

\section{Further Research Implication}

Studies with stronger designs need to be conducted to generate more supportive evidence regarding female adolescent reproductive health service utilization including urban and rural females to estimate their utilization patterns for reproductive health services, to assess factors affecting the utilization and finally to inform policy modifications and formulation.

\section{Acknowledgements}

First and for most, we give honor to God, the omnipotent for every protection he did to us. Also we would like to extend our deepest gratitude to Mr. Niguse Chere, Jimma University, Epidemiology department, data collectors, supervisors, study participants.

\section{Funding}

Jimma University funded this study.

\section{Conflict of Interest}

All authors declared as there was no conflict of interest.

\section{List of abbreviations}

$\begin{array}{ll}\text { AIDS } & \text { Acquired Immune Deficiency Syndrome } \\ \text { ANC } & \text { Antenatal Care } \\ \text { ASRH } & \text { Adolescent Sexual and Reproductive Health } \\ \text { ARH } & \text { Adolescent Reproductive Health } \\ \text { CSA } & \text { Central Statistical Agency } \\ \text { EDHS } & \text { Ethiopian Demographic and Health survey } \\ \text { EMDHS } & \text { Ethiopian Mini Demographic and Health } \\ & \text { survey } \\ \text { ETB } & \text { Ethiopian Birr } \\ \text { FP } & \text { Family Planning } \\ \text { HIV } & \text { Human Immune Virus } \\ \text { IEC } & \text { Information Education Communication } \\ \text { IFHP } & \text { Integrated Family Health Program } \\ \text { IUD } & \text { Intrauterine Device } \\ \text { PNC } & \text { Postnatal Care } \\ \text { RH } & \text { Reproductive Health } \\ \text { SNNPR } & \text { South Nation Nationalities and Peoples Region } \\ \text { SPSS } & \text { Statistical Package for Social Science } \\ \text { SRH } & \text { Sexual and Reproductive Health } \\ \text { STI } & \text { Sexually Transmitted Infections } \\ & \end{array}$

$\begin{array}{ll}\text { VCT } & \text { Voluntary Counseling and Testing } \\ \text { WHO } & \text { World Health Organization }\end{array}$

\section{References}

[1] Save the Children and UNFPA, Adolescent Sexual and Reproductive Health Tool kit in Humanitarian Settings, A Companion to the Inter-Agency Field Manual on Reproductive Health in Humanitarian Settings, 2009. Pp 1-8.

[2] Bernstein, S. and Hansen C. J. Public Choices, Private Decisions: Sexual and Reproductive Health and the Millennium Development Goals. New York: United Nations Millennium projects 2006.

[3] EWEC Technical Content Work stream Working Group on Adolescent Health, The Global Strategy for Women's, Children's and Adolescent Health 2.0 Realizing the health and wellbeing of adolescent, 2015, pp 11.

[4] United Nations Report of the International Conference on Population and Development Cairo, 13 September 1994 New York United Nations, 1995.

[5] FDREMOH, CSA, Ethiopia Mini Demographic and Health Survey 2014 Central Statistical Agency Addis Ababa, Ethiopia, 2014, pp 1-112.

[6] WHO, Pregnant adolescents: delivering on global promises of hope. WHO, 2006.

[7] African Population and Health Research Center (AP6T56T5HRC). Protecting in-School adolescents from HIV/AIDS, STI and unwanted pregnancy: evidence-based lessons for programs and policy. Policy brief No. 11, 2009 pp $1-2$.

[8] Gore FM, Bloem PJN, Patton GC, Ferguson J, Joseph V, Coffey C, Mathers CD. Global burden of disease in young people aged 10-24 years: a systematic analysis. The Lancet 377 (9783). 2011: 2093-2102 DOI 10.1016/S0140-6736 (11)60512-6.

[9] WHO Department of making pregnancy safer, MAPSNOTES, Adolescent Pregnancy Volume 1, No.1, October 2008.

[10] Ipas Ethiopia; Building healthy future for Ethiopia's youth; Addis Ababa, Ethiopia, 2014.

[11] UNAIDS/WHO, Epidemiological Fact Sheet on HIV and AIDS: Ethiopia 2008 Update. Geneva: UNAIDS. 2008.

[12] Ayalew T, Yeshigeta G: accessibility and utilization of adolescent reproductive health services in Jimma city: Ethiop J Health Sci. 200919 (2): 91-102.

[13] Central Statistical Agency [Ethiopia] and ICF International: Ethiopia Demographic and Health Survey 2011. Addis Ababa, Ethiopia and Calverton, Maryland, USA: Central Statistical Agency and ICF International; 2012.

[14] Cherie N, Tura G, Teklehymanot A, Reproductive health needs and service utilization among youths in west Badewacho woreda, Hadiya Zone, Journal of public health and epidemiology, 2015, 7 (4), pp. 145-153.

[15] FDREMOH National adolescent and youth reproductive health strategy FMOH, 2007. 
[16] International Planned Parenthood Federation (IPPF), 2007.

[17] Children's and Youth Affairs Organization (CYAO). Ethiopian youth: Basic challenges and prospects. Addis Ababa, Ethiopia, 1995.

[18] Senafikish A, Digsu N, Amsalu F, Zelalem B. Reproductive health service utilization and associated factors among adolescents (15-19 years old) in Gondar Town, Northwest Ethiopia. 2013, BMC Health Services Research 2013, 13: 294. http://www.biomedcentral.com/1472-6963/13/294.

[19] Gebreselassie B., Takele A, Bililign N, Adera A, Ayene Y, Woreta A, Kidan M, Assessment of Reproductive Health Service Utilization and Associated Factors Among Adolescents (15-19 Years Old) in Goba Town, Southeast Ethiopia, American Journal of Health Research, 2015; 3 (4): 203-212 doi: 10.11648/j.ajhr.20150304.12.

[20] Meskerem Abebe, Worku Awoke. Utilization of Youth Reproductive Health Services and Associated Factors among High School Students in Bahir Dar, Amhara Regional State, Ethiopia. Open Journal of Epidemiology, 2014, 4, 69-75 doi.org/10.4236/ojepi.2014.42012.

[21] Abajobir A. and Seme A. Reproductive health knowledge and services utilization among rural adolescents in east Gojjam zone, Ethiopia: a community-based cross-sectional study, BMC Health Services Research 2014, 14: 138, pp 4-8.

[22] Bam K, Haseen F, Kumar R, Newman M. S, Chaudhary A, Thapa R, Bhuyia I, Perceived Sexual and Reproductive Health Needs and Service Utilization among Higher Secondary School Students in Urban Nepal, American Journal of Public Health Research, 2015, Vol. 3, No. 2, pp 36-45.

[23] Biddlecom A, Munthali A, Singh S, and Woog V, Adolescents' views of and preferences for sexual and reproductive health services in Burkina Faso, Ghana, Malawi and Uganda African Journal of Reproductive Health. 2007; 11 (3): 99-100.

[24] Mapifuria M, Factors associated with utilization of Adolescent Sexual and Reproductive Health services offered at Harare Youth Friendly Corner by the youths in Harare Urban District, Dissertation of Master in Public Health Degree (unpublished), University of Zimbabwe, 2013 pp.

[25] Addis Ababa city administration education bureau, 2015.
[26] Dida N, Darega Band Takele A, Reproductive health services utilization and its associated factors among Madawalabu University students, Southeast Ethiopia: cross-sectional study, BMC Research Notes, 2015, 8: 8, DOI 10.1186/s13104-0150975-5.

[27] Tilahun, M., Mengistie, B., Egata, Gand Reda, A. A, Health workers attitude towards sexual and reproductive health services for unmarried adolescents in Ethiopia. Reproductive Health 2012, 9: 19, pp 1-7.

[28] Meskerem Abebe, Worku Awoke. Utilization of youth reproductive health services and associated factors among high school students in Bahir Dar, Amhara Regional State, Ethiopia. Open Journal of Epidemiology, 2014, 4, 69-75 http://dx.doi.org/10.4236/ojepi.2014.42012.

[29] Godia P, Youth friendly sexual and reproductive health service provision in Kenya: What is the best model? Nairobi, MOH, 2010. Pp 74-82.

[30] Warenius L, Faxelid E, Chishmb P, Musandu J, Ong any A, Nissen E, Nurse- midwives' attitude towards adolescent sexual and reproductive health needs in Kenya and Zambia. Reproductive health matters, 2006; 14: 119-128.

[31] Workneh H, Assessment of factors affecting RHSU among students in Bahir Dar University, science in maternity and reproductive health nursing (Unpublished), 2015, pp 40-42.

[32] Federal Democratic Republic of Ethiopia Central Statistical Agency Population Projection of Ethiopia for All Regions at woreda Level from 2014-2017, Addis Ababa, 2013, pp 54.

[33] WHO, Tools for assessing the operationality of district health systems guideline WHO Regional Office for Africa, Brazzaville, 2003.

[34] Adamchak S, Bond K, Mac Laren L, Magnani R, Nelson K, Seltzer J, A Guide to Monitoring and Evaluating Adolescent Reproductive Health Programs Part II: Instruments and Questionnaires Instruments and Questionnaires, 2000, pp 1270 .

[35] UNFPA, UNICEF, IPPF, Guideline Manual on Standards for the Youth Friendly Services, 2010, pp 6-22.

[36] World Bank, Poverty and Poverty Lines, 2014: www. Poverty tools.org/faq.htm. 